\title{
Social Isolation and Loneliness in Old Age: Review and Model Refinement
}

G. CLARE WENGER*, RICHARD DAVIES†, SAID SHAHTAHMASEBI+ and ANNE SCOTT*

\section{ABSTRACT}

This paper reviews the empirical literature on social isolation and loneliness and identifies a wide range of published correlates. Using data from a study conducted in North Wales, which included many of the same correlated variables, a statistical modelling technique is used to refine models of isolation and loneliness by controlling for co-variance. The resulting models indicate that the critical factors for isolation are: marital status, network type and social class; and, for loneliness: network type, household composition and health.

KEY WORDS - Isolation, loneliness, model, networks.

\section{Background}

Social isolation and loneliness have long been identified as problems associated with old age (Sheldon 1948; Halmos I 952). Although not always made explicit in the literature, social isolation refers to the objective state of having minimal contact with other people; while loneliness refers to the subjective state of negative feelings associated with perceived social isolation, a lower level of contact than that desired or the absence of a specific desired companion. As populations age these problems are increasingly viewed as a major concern (Bennett

* Centre for Social Policy Research and Development, University of Wales, Bangor, Gwynedd LL57 2DG, U.K.

$\dagger$ Centre for Applied Statistics, Lancaster University.

+ Northern and Yorkshire Regional Health Authority. 
г980; Mullins et al. i988; Christ and Muller г99 I) and absence of loneliness and isolation is seen as important for a good quality of life (Sinclair et al. 1990). In the context of social policy and service provision for elderly people the fact that biological reactions to stress may increase physical susceptibility to disease and mental illness (Dean and Lin 1977) indicates that amelioration of these stressful conditions can improve health as well as quality of life.

The importance of social isolation in social policy terms is implicit in the emphasis placed on social integration and support networks in the Griffiths Report (1988) and the Government White Paper (DoH I989), with the associated guidance (DoH r $990 a$ and $b$ ) and in its correlation with institutional admissions (Rodstein et al. 1976; Ross and Kedward 1976) and poor rehabilitation (Hyman 1972).

Loneliness has been described as the main problem associated with old age (Wilkes ${ }_{1978}$ ). It has been identified as a common presenting problem in referrals to social services (Stevenage Development Corporation 1973; Hazan 1980; Grant 1981; Sinclair et al. 1990; Jerrome I99I) and a significant correlate with entry to residential care (Townsend 1965; Wenger 1984a; Sinclair et al. 1990).

Social isolation and loneliness have been identified as susceptible to therapeutic interventions (Bennet 1980; Freeman 1988; Grant 1988; Mullins et al. 1988; Knipscheer I 988; Jerrome I99 I, 1992) and thus as important targets for preventive strategies (Goldberg 1979; Hadley et al. 1975; Mulligan and Bennett 1977/8; Grant I988; Jerrome I99 I). The reduction of isolation and loneliness is seen as a main aim by most personnel in the charitable groups which organise clubs for older people and by similar statutory day care providers (Jerrome I99 I). Changes in levels of isolation and loneliness have been used as outcome measures in the evaluation of various interventions (Challis I982).

The first part of this paper reviews the literature on social isolation and loneliness. The relationship between isolation and loneliness is discussed and the reported correlates of isolation and loneliness identified. Subsequently, a statistical modelling technique is employed in an effort to refine earlier analyses, based on longitudinal data from a study conducted with elderly people living in the community in North Wales.

While social isolation and loneliness are seen as common problems of old age, the prevalence of these problems is likely to have been overestimated. It has been suggested that social isolation is not widespread except among the very old (Peters and Kaiser r 985; Freeman 1988). However, advancing age predisposes people to those experiences which can lead to isolation: bereavement, relocation (moving) and retirement 
(Hovaguimian et al. I 988), although different patterns of isolation have been identified which include both those who become isolated in old age and those who are life-long isolates (Bennett I980, Wenger I992a).

The largest survey on loneliness, conducted in the United States by Harris and Associates (1974), found that for elderly people it was less important than fear of crime, poor health and inadequate income. The survey was repeated in $198 \mathrm{I}$ with similar findings (Harris et al. I98I). A European study found that the prevalence of loneliness shows no significant difference between age groups (Tornstam 1981).

\section{The correlates of isolation and loneliness}

Despite the absence of a direct link between isolation and loneliness (Wenger 1983,19846 ), many of the same factors are associated with both. Different writers have looked at different variables, some concentrating on demographic and others on behavioural correlates. Interpretations are not always consistent so that no unified model of isolation or loneliness exists.

Both isolation and loneliness have been shown to be more common for women than for men (Qureshi and Walker I989), but this is largely due to the fact that women are more likely to be widowed and living alone, both factors being important correlates for men and women. However, a study in the US (Mullins and Mushel 1992) found that men were more lonely than women. The association with advanced age (Wenger 1983) can also be explained in terms of the greater likelihood of being widowed and living alone, although some of the isolation associated with longevity results from outliving one's contemporaries (Hadley and Webb 1974). However, Bury and Holme (1990) found that even in a study of people over 90,6 I per cent said they were never lonely. Table I summarises the prevalence of loneliness from a range of studies.

In some studies living alone has been equated with social isolation and in all studies of isolation living alone appears to be a sine qua non of the definition, for while not all those living alone are isolated, nearly all those who are isolated live alone. Loneliness is not directly associated with living alone. Many who live alone live fully integrated socially active lives (Larsen et al. 1985), however, loneliness is more common amongst those living alone (Havinghurst 1978; Hunt 1978; Wenger I983). The evidence indicates that intimate relationships outside the family may be more important than family relationships (Abrams 1974; Bengtson and Kuypers 1985). 
TABLE I. Prevalence of loneliness in adults aged $65+(\%)$

\begin{tabular}{|c|c|c|c|c|}
\hline & $\begin{array}{l}\text { Very/often } \\
\text { lonely }\end{array}$ & $\begin{array}{l}\text { Sometimes } \\
\text { lonely }\end{array}$ & $\begin{array}{l}\text { Never/rarely } \\
\text { lonely }\end{array}$ & Sample Characteristics \\
\hline \multicolumn{5}{|l|}{ U.K. Studies: } \\
\hline Sheldon (1948) & 10 & 7 & 84 & Urban \\
\hline Tunstall (1966) & 9 & - & - & \\
\hline Goldberg (1970) & I 3 & $3^{6}$ & $5^{\circ}$ & Social Service Clients \\
\hline $\begin{array}{l}\text { Townsend and } \\
\text { Tunstall (1973) }\end{array}$ & II & 33 & $5^{6}$ & Living alone \\
\hline Hunt $(1978)$ & $13^{1}$ & - & - & \\
\hline \multicolumn{5}{|l|}{ Wenger (1984) } \\
\hline Self-assessed & 5 & 19 & 76 & Rural Population \\
\hline Aggregate measure & 9 & 29 & 63 & \\
\hline Jones et al. ( $\left(\mathrm{I}^{8} 5\right)$ & 5 & 19 & 76 & Urban \\
\hline & 2 & 14 & 84 & Rural \\
\hline $\begin{array}{l}\text { Quereshi and } \\
\left.\text { Walker ( } 19^{8} 9\right)\end{array}$ & $12^{2}$ & - & - & \\
\hline \multicolumn{5}{|l|}{ Other countries: } \\
\hline Shanas et al. ( ( 968$)$ & 7 & 21 & 72 & $\begin{array}{l}\text { Denmark, UK \& } \\
\text { USA }\end{array}$ \\
\hline Harris et al. (1974) & I $2^{1}$ & - & - & USA \\
\hline Kivett (1979) ${ }^{3}$ & 16 & 42 & 43 & USA - rural \\
\hline Harris et al. $(\mathrm{r} 98 \mathrm{I})$ & 13 & - & - & USA \\
\hline Power (1980) & 14 & 25 & $6 I$ & $\begin{array}{l}\text { Republic of Ireland - } \\
\text { Living alone }\end{array}$ \\
\hline Clifford (1990) & I 5 & 20 & 65 & Republic of Ireland \\
\hline $\begin{array}{l}\text { Huijsman and de } \\
\text { Klerk (r993) }\end{array}$ & 10 & 17 & 73 & The Netherlands \\
\hline
\end{tabular}

1 Loneliness experienced as serious problem.

2 Aged $75+$.

3 Based on discriminant analysis.

Isolation has also been identified as more common amongst those who are widowed (Berardo 1967; Carey 1977; Qureshi and Walker 1989) and while the majority of widowed people are women, it has been suggested that isolation can be more extreme for widowed men (Dibner 198I). However, the relationship between widowhood and loneliness is reported in nearly all studies, some of which have noted that it is most intense in early widowhood (Sheldon 1948; Berardo 1967; Shanas et al. 1968; Townsend and Tunstall 1973; Whittington 1977; Hunt 1978; Kivett 1979; Power 1980; Wenger 1983), when the loss of an intimate companion is most painful.

It has been claimed that loneliness amongst widows may be ameliorated by visits from children. However, it has been found that such visits make little impact on loneliness (Hadley et al. 1975; Arling 1980), and very old widows living with children are frequently amongst the most lonely (Townsend and Tunstall 1973; Wenger 1983). Absence 
of children has been identified as being associated with both isolation (Palmore 1976) and loneliness (Shanas et al. 1968; Townsend and Tunstall I 973), but Weeks and Cuellar ( 198 I ) found that while elderly people may turn to the family for instrumental help, they are least likely to do so in times of loneliness. In contrast, a study in Sweden found that loneliness is related inversely to frequency of contact with children and friends but not neighbours (Berg et al. I 98 I). Mullins and Mushel (1992) found that loneliness was unrelated to the availability of spouse or children but that the existence of friends was significant. The importance of friends has also been identified by other authors (Wenger I983; Jerrome I99I). It has been shown that most of the objective measures of social isolation are unrelated to the subjective measures of well-being, although companionship and the availability of confidant relationships are significant (Chappell and Badger 1989). Other research has shown that those without a confiding relationship are more subject than others to depression (Murphy 1982).

Singleness has also been associated with both isolation (Shanas et al. r 968; Lowenthal and Robinson 1976; Palmore 1976) and loneliness (Shanas et al. 1968; Hadley and Webb 1974; Kivett 1979; Wenger I $984 b$ ), although Townsend and Tunstall (1973) claim that single people are less lonely. Part of the reason for such disagreement is likely to stem from bivariate analyses without any control variables. In addition to marital status, loneliness has been associated with loss of any close relationship (Townsend and Tunstall 1973; Hadley and Webb 1974; Mullins et al. 1988); changes in social contacts (Kivett 1979); reliance on a single close relationship (Hadley and Webb 1974); and, on loss in general (Shanas et al. 1968; Power 1980).

Other authors (Shanas et al. 1968; Abrams 1974) emphasise that loneliness is more closely associated with loss than with isolation. Thus loneliness is found to be more common among recent isolates than lifelong isolates (Townsend and Tunstall 1973; Bennett 1980) and associated with the experience of loss or death of members of the close social network (Townsend ig68; Hadley and Webb r974; Mullins et al. 1988). Both isolation and loneliness have been identified as being associated with retirement migration and thus disruption of the social network (Whittington 1977; Wenger 1984 $b$; Fitzgerald 1986). This latter point is in contrast with long-standing isolation which is more often associated with a failure to develop a social network in earlier life (Hadley and Webb i 974).

Social class status has been found to be associated with isolation but not loneliness. Working class older people appear to be more likely than others to become isolated (Blum I 964 ; Lowenthal and Robinson 1976 ). 
Working class elders are also more likely to become depressed (Murphy 1982).

Both isolation and loneliness are associated with poor health and/or loss of mobility. Evidence presented elsewhere suggests that social stress may trigger poor health (Dean and Lin 1977; Murphy 1987; Grant I 988), although loneliness may result from restricted contacts with others due to ill health (Jerrome I99I). Loneliness is associated with the amount of contact with health professionals, and use of medicines (Asiel 1987). It has also been shown to be connected with general disability (Jones et al. 1985). The causal relationship is not clear cut. Isolation and loneliness may lead to ill health, the causal link may be in the other direction or the connections may be circular. Correlations have been found between poor health and isolation (Lowenthal I 964 ; Hadley and Webb 1974; Lowenthal and Robinson I 976; Lynch 1977) and between poor health and loneliness (Townsend and Tunstall I 973; Kivett I979; Power 1980; Wenger 1984 $b$; Jones et al. 1985; Asiel 1987; Mullins et al. I988). Mullins et al. ( 1988 ) go so far as to say that health is the best predictor of loneliness. Mortality has been associated with both isolation (Berkman and Syme I979; Abrams 1983) and loneliness (Abrams ig83).

The main link between loneliness and mental illness appears to be the likelihood of lonely people becoming depressed (Thompson 1973). The relationship between depression and loneliness is further emphasised by findings that link childhood loss or an unsafe childhood with later depression (Brown and Harris 1978) and loneliness in adulthood (Seabrook 1973; Tornstam 1989). However, at least one author, taking a psychoanalytic approach finds that both neglect and too much attention in the context of a secluded childhood can lead to loneliness in old age (Andersson 1990). Severe life events in the preceding year have also been linked to the onset of depression (Murphy 1982,1983 ).

Isolation and loneliness have also been shown to be associated with admissions to residential care (Townsend and Tunstall 1973; Ross and Kedward 1976; Wenger 1984a; Koedoot and Hommel 1993), while those who are isolated demonstrate poor stroke rehabilitation levels (Hyman 1972). Jerrome (1982) and Elias ( 1986 ) have noted that dying is both a lonely and for many an isolated experience.

Both isolation (Brocklehurst 1978) and loneliness (Wenger $1984 b$, $1992 b$ ) have been associated with low morale, although Wenger $(1984 b)$ found that those who were isolated had better health and higher morale than those who were lonely. While poor physical health is related to both social isolation and loneliness, only isolation appears to be highly correlated with mental disorder (Lowenthal 1964 ; Hadley 
$\mathrm{T}_{\mathrm{AB} \text { B E 2. Summary of reported correlates }}{ }^{1}$ of isolation and loneliness

\begin{tabular}{lcc}
\hline & Isolation & Loneliness \\
\hline Age $^{2}$ & $\times$ & $\times$ \\
Male sex & $\times$ & $\times$ \\
Widowhood & $\times$ & $\times$ \\
Singleness & $\times$ & $\times$ \\
Living alone & $\times$ & $\times$ \\
Childlessness & $\times$ & $\times$ \\
Retirement migration & $\times$ & $\times$ \\
Poor health & $\times$ & $\times$ \\
Restricted mobility & $\times$ & $\times$ \\
Mortality & $\times$ & $\times$ \\
Admission to institutional care & $\times$ & $\times$ \\
Low morale & $\times$ & $\times$ \\
Working class status & $\times$ & \\
Poor rehabilitation & $\times$ & \\
Mental illness & $\times$ & \\
Absence of friends & & $\times$ \\
Loss & & $\times$ \\
Depression & & $\times$ \\
\hline
\end{tabular}

1 As specified in the table, all associations are positive.

${ }^{2}$ Bold type indicates variables also available in North Wales study discussed below.

and Webb I974; Gottlieb and Schroter 1978; Salloway 1983; Wilkin et al. 1985 ; Freeman 1988 and Hovaguimian et al. 1988 ) and Lowenthal (1964) notes that this is more marked when isolation develops late in life. This suggests a causal relationship, i.e. (late developing) isolation may lead to mental disorder rather than the other way round. There is an indication here that loss is associated with mental health problems. However, only prospective studies can fruitfully examine these links.

The identified correlates of isolation and loneliness are summarised in Table 2. In the remainder of this paper we present statistical models of isolation and loneliness which control for interrelationships between variables.

\section{Findings from North Wales study}

The findings presented in the remainder of this paper come from the first phase of a four phase longitudinal study of ageing conducted in North Wales 1978-1991. The sample was selected from the total community of elderly people living at home in a range of representative settlement types in rural North Wales, and the achieved sample was 
representative of the numbers living in different community types for that rural region. The project was based on a 1979 survey of 534 elderly people $65+$ living in the community. Survivors have been reinterviewed in $1983,1987,1991$ and 1995.

We present here the results of cross-sectional multivariate analyses of the baseline 1979 data. The objective is to arrive at refined models of isolation and loneliness which identify and include the main explanatory variables from our list of possible correlates.

\section{Building statistical models of isolation and loneliness}

Models are established for (1) social isolation, (2) loneliness based on an aggregate measure and (3) self-assessed loneliness.

Isolation was measured on an aggregate scale based upon eight objective items : lives alone; has no close relatives; never visits relatives or friends; has no contact with neighbours; has no telephone; is alone for more than 9 hours a day; lives more than $5^{0}$ years from nearest neighbour; and is housebound. One isolation point was scored for each item, giving a maximum isolation measure (IM) score of 8 and a minimum of 0 .

An aggregate scale was also designed to measure loneliness but, in this case, the contributing items had a subjective emphasis. Only one of the questions actually mentioned loneliness (although another item allowed loneliness as an element in the response), thus seeking to overcome the stigma of loneliness and resistance to admitting that one was lonely (see Wenger, 1983). The eight items were: feels lonely much of the time; does not see enough of friends and relatives; does not meet enough people; has no one to confide in; wishes for more friends; has no one to ask favours of; has no real friends in the area; and spent the previous Christmas alone and lonely. The last item was coded from the response to an open question in which 'alone by choice' was another category. This loneliness measure is referred to subsequently as LM.

The third measure is a self-assessment of loneliness (SAL) for each respondent, with five response categories. This item was reduced to a two-category variable with 'never' and 'rarely' lonely combined into a 'not lonely' category, and 'sometimes', 'often' and 'most of the time' combined into a 'lonely' category.

The software package GLIM (Francis et al. 1993) was used for the analyses. A conventional linear regression model was appropriate for the continuous response variable IM and a logistic regression model for the binary response variable SAL. The response variable $\mathrm{LM}$ was more 
problematic. It is positively skewed with around 60 per cent of the responses on the lowest end of the scale. It was decided to recode this continuous variable into three categories: 'not lonely' (a score of o), 'medium' (a score of 1 or 2 ) and 'high' (a score of 3 or higher) on the basis of earlier work (see Wenger $1984 b$ ). A multinominal logistic model was then fitted to these data.

Eleven explanatory variables supported by previous work (see Table 2 - marital status constituted one variable, subsuming widowhood and singleness) were available for inclusion in the models. The list was augmented by seven more measures: number of years widowed, income, network type (Wenger I989, see appendix), ethnicity (Welsh/ non-Welsh); wish for more friends, having a confidant, and the time they have known their confidant. Seven variables dependent on the respondent's subjective assessment or response, or feelings, are classified as subjective (self-assessed health; activities limited by health; morale; presence of local friends; desire for more friends; presence of a confidant and length of time known confidant). The number of years respondent has known a confidant is included because the perception of having a confidant may be subjective. The analyses seek to establish models on the basis of the objective variables and then to test for the effect of subjective variables over and above the objective variables. With this pragmatic approach, it is possible to obtain some indication as to whether the role of subjective variables is an additional and distinct direct effect, an intervening effect, or the result of complex interaction with the objective variables.

A forward substitution method was used to guide the selection of a preferred model for each response variable. Explanatory variables were entered in the model one at a time and their effect was tested for statistical significance. The most significant variable was then added to the model and the process repeated until none of the remaining variables was significant. In the case of two or more variables of similar significance at any iteration, two or more models were developed and goodness-of-fit criteria were used to choose between the final results. At each iteration, variables not significant at 5 per cent were dropped from the analysis (see Appendix B).

\section{Isolation model}

Since household composition and the existence of close relatives contributed towards the definition of the isolation measure (IM), these variables (household composition and childlessness) were excluded from the analysis of IM. All the other variables except age of arrival in 
present community, ethnicity and the two health variables are significant at a 5 per cent level when included on their own in the model. Marital status is the most significant of the objective variables and enters the model first. After controlling for this variable, age, sex and income cease to be significant. Subsequently, the variables number of years widowed, social class, and network type enter the model in that order.

In stage 2, with the parameter estimates of the objective model held fixed, the variable 'length of time they have known a confidant' is highly significant and enters the model. All but morale then cease to be significant. Thus, at this stage, the model includes two subjective variables in addition to the objective variables from stage $I$.

When model fitting is repeated without distinguishing between objective and subjective variables, exactly the same set of explanatory variables appear in the final model; the results are encouragingly robust.

The resulting Model of Isolation includes: marital status; number of years widowed; social class; support network type; morale; and length of time respondent has known their present confidant.

\section{Self-assessed Loneliness (SAL) model}

For the analysis of self-assessed loneliness the objective variables age, parenthood, arrival age, social class and ethnicity are all non-significant at the 5 per cent level when included on their own in the model. Marital status again enters the model first. Controlling for this variable, sex, number of years widowed and income cease to be significant. The two remaining objective variables, network type and household composition, are both included in the final model for stage I.

Because of the nature of the logistic distribution (having fixed variance) the parameters of the objective model cannot be fixed when testing for the subjective variables. Having arrived at a preferred model for the objective variables, subjective variables are introduced into this model. SAL was a defining variable for morale, so morale was not considered for inclusion. All the other subjective variables, except the presence of local friends, are significant when included on their own, and the wish for more friends, self-assessed health and length of time respondent has known their confidant enter the model in that order. The objective variables remain significant after inclusion of subjective variables in the model; again, the models are encouragingly robust.

The resulting Model of Self-Assessed Loneliness includes: marital status; household composition; support network type; self-assessed health; 
desire for more friends and length of time respondent has known their confidant.

\section{Loneliness (aggregate measure) LM model}

For the analysis of the LM, network type enters the model first. Controlling for this variable, age and number of years widowed cease to be significant. At this round, household composition and ethnicity were both significant. Each of these variables remains significant when controlling for the other; both variables are included in the stage I model.

Once again, the parameters of the objective model cannot be fixed because of the nature of the logistic distribution. All the subjective measures, apart from the two health measures, are defining variables for LM. They are, therefore, ignored in the analysis. Self-assessed health enters first in stage 2. This does not affect the objective model, but health limited activities ceases to be significant.

The resulting Model of the Loneliness Measure, includes household composition; support network type; ethnicity and self-assessed health.

\section{Discussion of the models}

Using a multivariate modelling technique, it has been possible to refine the models of isolation and loneliness, reducing the number of significant correlates and identifying those which remain important when allowing for the associations between variables.

\section{Isolation}

In refining the model of isolation, the number of correlates was reduced from the 12 which are significant on their own to just 6 variables. The parameter estimates for the stage I model and for the final model including both objective and subjective variables are given in Table 3 . (The parameter estimates for the subjective variables at stage 2, when the objective parameters were fixed at their Stage I values, were close to those of the final model.). The coefficients for the objective variables change little when the subjective variables are added, indicating that the model gives a robust picture of the effect of the objective variables.

The results suggest that the variable marital status is significantly related to social isolation: married respondents appear to be less likely to be isolated than those who have never married, or have been widowed. Moreover, for the widowed, isolation tends to increase with 
TABLE 3. Isolation measure: Model fitting results using cross-sectional method ( $o=$ not isolated; $8=$ very isolated)

\begin{tabular}{|c|c|c|c|c|}
\hline & \multicolumn{2}{|c|}{ Stage I } & \multicolumn{2}{|c|}{ Final Model } \\
\hline & p.e. & s.e. & p.e. & s.e. \\
\hline \multirow[t]{2}{*}{ Constant } & I.1 7 & 0.24 & 1.89 & 0.55 \\
\hline & \multicolumn{4}{|c|}{ Objective Variables } \\
\hline & 0.00 & \\
\hline married & -1.19 & 0.18 & -1.15 & 0.17 \\
\hline widowed & 0.03 & 0.16 & 0.03 & 0.16 \\
\hline \multicolumn{5}{|l|}{ Social Class } \\
\hline I/II & 0.00 & & 0.00 & \\
\hline III/IV & $0.4^{1}$ & 0.12 & 0.43 & 0.12 \\
\hline $\mathrm{V}$ & 0.49 & 0.16 & 0.49 & 0.15 \\
\hline military/no class & 0.27 & 0.29 & 0.28 & 0.27 \\
\hline Years widowed & 0.20 & 0.04 & 0.15 & 0.04 \\
\hline \multirow{6}{*}{$\begin{array}{l}\text { Network type } \\
\text { local family dependent } \\
\text { locally integrated } \\
\text { locally self-contained } \\
\text { wider community focused } \\
\text { private }\end{array}$} & 0.00 & & 0.00 & \\
\hline & -0.09 & 0.15 & 0.07 & 0.15 \\
\hline & 0.41 & 0.17 & $0.4^{8}$ & 0.17 \\
\hline & -0.02 & 0.20 & 0.05 & 0.19 \\
\hline & 0.53 & 0.23 & $0.5 \mathrm{I}$ & 0.22 \\
\hline & \multicolumn{4}{|c|}{ Subjective Variables } \\
\hline \multicolumn{5}{|l|}{ Morale } \\
\hline low & & & 0.00 & \\
\hline medium & & & -0.66 & 0.39 \\
\hline high & & & -0.93 & $0.3^{8}$ \\
\hline \multicolumn{5}{|l|}{ Time known confidant } \\
\hline$<$ I year & & & 0.00 & \\
\hline $1-3$ years & & & -0.07 & 0.34 \\
\hline $4^{-5}$ years & & & 0.25 & 0.33 \\
\hline $6-10$ years & & & -0.03 & $0.3^{2}$ \\
\hline II -20 years & & & -0.06 & $0.3^{2}$ \\
\hline $21-30$ years & & & 0.90 & $0.3^{6}$ \\
\hline $3^{1}+$ years & & & 1.40 & $0.4^{2}$ \\
\hline $\mathrm{R}^{2}$ & \multicolumn{2}{|c|}{$0.3^{2}$} & \multicolumn{2}{|c|}{0.39} \\
\hline
\end{tabular}

duration of widowhood. Older working class people are more likely to be socially isolated in addition to the effect of marital status. This may reflect lower levels of income and access to transport as well as life-style. Support network type remains significant even when marital status and social class are controlled for. Those with privatised or householdfocused life-styles are more likely to be isolated. The locally integrated network type, which includes higher numbers of friends and involvement in community groups, is associated with the lowest isolation scores. 
T A B LE 4. Cross-sectional analysis of self-assessed loneliness - model fitting results $(\mathcal{N}=498)(I=$ lonely; $O=$ not lonely $)$

\begin{tabular}{|c|c|c|c|c|}
\hline & \multicolumn{2}{|c|}{ Stage I } & \multicolumn{2}{|c|}{ Final Model } \\
\hline & p.e. & s.e. & p.e. & s.e. \\
\hline \multirow[t]{2}{*}{ Constant } & 0.57 & 0.41 & 0.20 & 0.93 \\
\hline & \multicolumn{4}{|c|}{ Objective variables } \\
\hline \multicolumn{5}{|l|}{ Marital status } \\
\hline married & 0.28 & 0.67 & $0.6 !$ & 0.77 \\
\hline widowed & 1.34 & 0.34 & 1.71 & 0.40 \\
\hline \multicolumn{5}{|l|}{ Network type } \\
\hline local family dependent & 0.00 & & 0.00 & \\
\hline locally integrated & -1.28 & 0.34 & -0.9 & 0.37 \\
\hline local self-contained & -0.40 & 0.36 & -0.21 & $0.4^{1}$ \\
\hline wider community focused & -1.64 & 0.47 & -1.40 & 0.53 \\
\hline private restricted & 0.18 & 0.44 & 0.14 & 0.49 \\
\hline \multicolumn{5}{|l|}{ Household composition } \\
\hline alone & 0.00 & & 0.00 & \\
\hline with spouse & -1.06 & 0.67 & -1.57 & 0.76 \\
\hline with younger & -1.46 & $0.3^{6}$ & -1.55 & 0.40 \\
\hline \multirow[t]{2}{*}{ with older } & -1.71 & 0.66 & -2.02 & 0.79 \\
\hline & \multicolumn{4}{|c|}{ Subjective variables } \\
\hline \multicolumn{5}{|l|}{ Wish for more friends } \\
\hline yes & & & 0.00 & \\
\hline no & & & -1.84 & 0.37 \\
\hline \multicolumn{5}{|l|}{ State of health } \\
\hline good/excellent & & & 0.00 & \\
\hline all right for age & & & 0.68 & 0.30 \\
\hline fair/poor & & & 1. 56 & 0.35 \\
\hline \multicolumn{5}{|l|}{ Time known confidant } \\
\hline$<$ I year & & & 0.00 & \\
\hline $1-3$ years & & & 0.65 & $0.7^{8}$ \\
\hline $4-5$ years & & & $-0.5^{2}$ & 0.80 \\
\hline-6 -10 years & & & -0.50 & 0.74 \\
\hline $11-20$ years & & & $-0.5 \mathrm{I}$ & 0.73 \\
\hline $2 \mathrm{I}-30$ years & & & 0.69 & 0.82 \\
\hline $3^{1}+$ years & & & 0.73 & 0.95 \\
\hline Log likelihood & \multirow{2}{*}{\multicolumn{2}{|c|}{$\begin{array}{c}-235.0 \\
487\end{array}$}} & \multirow{2}{*}{\multicolumn{2}{|c|}{$\begin{array}{c}-198.0 \\
478\end{array}$}} \\
\hline Degrees of freedom & & & & \\
\hline
\end{tabular}

The significantly higher levels of isolation for those who have known their confidant for more than 20 years is difficult to explain. The association with low morale is likely to reflect the lowered morale of those who become socially isolated but may equally well indicate withdrawal on the part of those whose morale is low.

What seems clear from this analysis is that social isolation appears to arise from factors which are largely beyond the control of the individual 
and which are, therefore, not obviously susceptible to amelioration. Practitioners should be aware of the predisposing factors and maintain closer monitoring and surveillance of those recognised to be at risk of social isolation.

\section{Loneliness}

We have produced two separate loneliness models, one based on selfassessment and another based on an aggregate measure, which it has been suggested is more objective and overcomes feelings of stigma which may influence responses (Wenger 1983).

For self-assessed loneliness the number of significant correlates was again halved from 12 to 6 in the multivariate analysis. Only 7 explanatory variables were significant on their own for the aggregate loneliness measure and these were reduced to 4 by the multivariate analysis. The parameter estimates for the loneliness models are given in Tables 4 and 5 respectively.

Again, the general pattern of the parameter estimate for the objective variables in the Stage I models is maintained in the final models when the subjective variables are added.

In the SAL model, the parameter estimates for marital status and household composition increase with the inclusion of the subjective variables, while those for network type generally decrease. In a logistic model, this is consistent with the effect of the subjective variables being independent of marital status and household composition, but interacting with network type to reduce its effect. Network type is based upon both demographic criteria, such as availability of local kin, and social activity. It may be that the subjective variables are acting to substitute for part of the social component.

The inclusion of state of health in the model for LM has very little effect on the model, although there is some limited evidence for an interaction with network type as for SAL. This is not surprising since shifts in support network type are associated with the deterioration of health and/or growing frailty. Shifts are not inevitable but where they do occur, they are modally from more to less independent network types (Wenger and Scott i 994).

Three variables are significant in both of the loneliness models: network type, household composition and self-assessed health. Unsurprisingly, those with support networks which provide high levels of social contact and interaction-locally-integrated and wider community-focused networks - are less likely to be lonely. In the LM model, the effect increases steadily across the three categories: 'not 
TABLE 5. Cross-sectional analysis of loneliness measure-model fitting results $\left(\mathcal{N}=49^{8}\right)$ (modelling probability of loneliness categories)

\begin{tabular}{|c|c|c|c|c|}
\hline & \multicolumn{2}{|c|}{ Stage I } & \multicolumn{2}{|c|}{ Final Model } \\
\hline & p.e. & s.e. & p.e. & s.e. \\
\hline \multicolumn{5}{|l|}{ Constant } \\
\hline Group (2) & 0.14 & 0.30 & -0.30 & 0.35 \\
\hline \multirow{2}{*}{ Group (3) } & -0.43 & 0.39 & -0.82 & $0.4^{6}$ \\
\hline & \multicolumn{4}{|c|}{ Objective Variables } \\
\hline \multicolumn{5}{|l|}{ Network Type* } \\
\hline Group 2.LFD & 0.00 & & 0.00 & \\
\hline Group 2.LI & -1.17 & $0.3^{2}$ & -1.04 & 0.33 \\
\hline Group 2.LSC & -0.25 & 0.35 & -0.15 & 0.35 \\
\hline Group 2 WCF & -1.25 & $0.4^{2}$ & -1.08 & 0.43 \\
\hline Group 2.PR & 0.34 & 0.45 & $0.4^{2}$ & 0.46 \\
\hline Group 3.LFD & 0.00 & & 0.00 & \\
\hline Group 3.LI & -2.65 & 0.54 & $-2.4^{8}$ & 0.54 \\
\hline Group 3.LSC & -0.99 & 0.47 & -0.82 & $0.4^{8}$ \\
\hline Group 3.WCF & -2.20 & 0.62 & -2.00 & 0.63 \\
\hline Group 3.PR & 0.07 & 0.55 & -0.22 & 0.55 \\
\hline \multicolumn{5}{|l|}{ Household Composition } \\
\hline Group 2. alone & 0.00 & & 0.00 & \\
\hline Group 2. with spouse & -0.82 & 0.27 & -0.86 & 0.27 \\
\hline Group 2. with younger & -0.97 & 0.33 & -0.90 & 0.33 \\
\hline Group 2. with older & -1.15 & $0.4^{8}$ & -1.15 & $0.4^{8}$ \\
\hline Group 3. alone & 0.00 & & 0.00 & \\
\hline Group 3. with spouse & -0.50 & $0.3^{8}$ & $-0.5^{8}$ & 0.39 \\
\hline Group 3. with younger & -0.95 & 0.47 & -0.87 & 0.47 \\
\hline Group 3. with older & -2.11 & 1.03 & -2.13 & 1.03 \\
\hline \multicolumn{5}{|l|}{ Ethnicity } \\
\hline Group 2. Welsh & 0.00 & & 0.00 & \\
\hline Group 2. non-Welsh & 0.75 & 0.26 & 0.77 & 0.26 \\
\hline Group 3. Welsh & 0.00 & & 0.00 & \\
\hline \multirow[t]{2}{*}{ Group 3. non-Welsh } & 0.93 & $0.3^{6}$ & 0.93 & $0.3^{6}$ \\
\hline & \multicolumn{4}{|c|}{ Subjective Variables } \\
\hline \multicolumn{5}{|l|}{ Health } \\
\hline Group 2. good & & & 0.00 & \\
\hline Group 2. all right & & & 0.44 & 0.25 \\
\hline Group 2. fair/poor & & & 0.85 & $0.3^{\circ}$ \\
\hline Group 3. good & & & 0.00 & \\
\hline Group 3. all right & & & 0.14 & $0.3^{8}$ \\
\hline Group 3. fair/poor & & & 0.96 & 0.41 \\
\hline Log likelihood & & & & \\
\hline Degrees of freedom & & & & \\
\hline
\end{tabular}

lonely', 'medium' and 'high'. Living with others and maintaining good health may, however, mitigate the effects of poor network support. These two factors and ethnicity discriminate mainly between the 'not lonely' and 'medium/high loneliness' groups. 
An earlier analysis (Wenger 1983 ), comparing self-assessed with LM loneliness found that widows appeared to be more willing to admit to loneliness and suggested that self-assessment may under-measure loneliness for other groups. The presence of marital status only in the SAL model is consistent with this conclusion. The wish for more friends was used as an item in the LM and so was omitted from the modelling exercise for this reason. The presence of ethnicity in the LM model is also significant and it was suggested earlier (Wenger $19^{8} 3$ ) that those who had moved into Wales, many on retirement, may also be unwilling to admit to loneliness, explaining why ethnicity is not significant for the SAL model. There are parallels here with a recent US study (Mullen and Mushel 1992) which found loneliness to be related to gender, health status, economic condition, need for affection and the desire to be part of a social network.

The variable 'time known confidant' entered the model for selfassessed loneliness last of the six variables. Although the overall effect was just significant $(P=0.04)$, the individual parameter estimates are all smaller than their standard errors and do not show a consistent trend. Since having a confidant was not significant when other variables were controlled for, it is likely that this apparent effect is an artefact of the data.

The differences between the SAL and the LM models alert practitioners to remain aware of the stigma of loneliness, which may not be admitted by those who have no socially acceptable reason to be lonely, such as being widowed. Again, two of the major contributory factors to loneliness - network type and household composition - are not susceptible to amelioration. Curative or palliative treatment may, however, reduce the impact of poor health. Here too practitioners need to be aware of the predisposing factors.

\section{Discussion of the results}

The results of the model fitting are summarised in Table 6 and 7. Table 6 shows which of the variables in the North Wales Study had previously been identified as associated with isolation and/or loneliness (Table 2). Four variables, age, gender, childlessness and retirement migration cease to be significant for any of the measures when controlling for the other variables in a multivariate analysis (although ethnicity probably acts as a proxy for retirement migration in the aggregate loneliness measure). 
TA B LE 6. Reconsideration of reported correlates of isolation and loneliness

\begin{tabular}{|c|c|c|c|c|c|}
\hline & \multirow{2}{*}{\multicolumn{2}{|c|}{ Isolation }} & \multicolumn{3}{|c|}{ Loneliness } \\
\hline & & & \multirow{2}{*}{ Literature } & \multicolumn{2}{|c|}{ Cross-sectional Modelling } \\
\hline & Literature & Cross-sectional & & (Self-assessed) & (Aggregate \\
\hline Age & $x$ & & $x$ & & \\
\hline Gender & $x$ & & $x$ & & \\
\hline Marital status & $x$ & $x$ & $x$ & $x$ & \\
\hline Houschold composition & $x$ & $\mathrm{D}$ & $x$ & $x$ & $x$ \\
\hline Childlessness & $x$ & $\mathrm{D}$ & $x$ & & \\
\hline Retirement migration & $x$ & & $x$ & & \\
\hline Self-assessed health & $x$ & & $x$ & $x$ & $x$ \\
\hline Restricted mobility & $x$ & D & $x$ & & \\
\hline Morale & $x$ & $x$ & $x$ & (D) & (D) \\
\hline $\begin{array}{l}\text { Social class } \\
\text { Local friends }\end{array}$ & $x$ & $x$ & $x$ & $x$ & \\
\hline Years widowed & & $x$ & & & \\
\hline Network type & & $x$ & & $x$ & $x$ \\
\hline Ethnicity & & & & & $x$ \\
\hline Time known confidant & & $x$ & & $x$ & \\
\hline
\end{tabular}

$\mathrm{D}=$ defining variable.

TABLE 7. Comparison of computer multi-variate models

\begin{tabular}{|c|c|c|}
\hline Isolation (Table 3 ) & $\begin{array}{l}\text { Self-assessed Loneliness } \\
\text { (Table 4) }\end{array}$ & $\begin{array}{l}\text { Aggregate Loneliness } \\
\text { Measure (Table 5) }\end{array}$ \\
\hline $\begin{array}{l}\text { Objective measures: } \\
\text { Singleness or widowhood } \\
\text { Length of widowhood } \\
\text { Working class status }\end{array}$ & Widowhood & \\
\hline $\begin{array}{l}\text { Local self-contained or } \\
\text { private restricted network } \\
\text { (Living alone was defining } \\
\text { factor for isolation) }\end{array}$ & $\begin{array}{l}\text { Family dependent, local } \\
\text { self-contained or private } \\
\text { restricted network } \\
\text { Living alone }\end{array}$ & $\begin{array}{l}\text { Family dependent, local } \\
\text { self-contained or private } \\
\text { restricted network } \\
\text { Living alone } \\
\text { Being non-Welsh }\end{array}$ \\
\hline $\begin{array}{l}\text { Subjective measures: } \\
\text { Low morale } \\
\text { Length of time known } \\
\text { confidant } \\
\text { (Houseboundedness was a } \\
\text { defining factor for isolation) }\end{array}$ & $\begin{array}{l}\text { Self-assessed health as only } \\
\text { fair/poor } \\
\text { Desire for more friends }\end{array}$ & $\begin{array}{l}\text { Self-assessed health as only } \\
\text { fair/poor }\end{array}$ \\
\hline
\end{tabular}


Three variables are present in all three models: household composition, morale and support network type. However, only network type is not included in the operational definitions of the variables of interest. Household composition (i.e. living alone) was a defining item for isolation, and the Philadelphia Geriatric Center morale measure used includes a loneliness component. Two further variables are associated with isolation and self-assessed loneliness but not with the aggregate loneliness measure: marital status and the length of time respondents have known a confidant. Singleness and widowhood are associated with social isolation, but only widowhood with self-assessed loneliness (Table 7). Of these five variables three had been previously identified as associated with both isolation and loneliness. However, two new shared correlates have been identified: support network type and length of confidant relationship.

Two additional variables were identified as significant correlates of isolation but not loneliness: social class and number of years widowed. Restricted mobility (houseboundedness) was a defining item for isolation. The association with social class (working class status) has previously been identified but the number of years widowed is a new correlate suggesting that the social isolation of widows increases over time.

Three variables are identified as correlates of loneliness but not isolation: self-assessed health, ethnicity and the desire for more friends. Health and friends have previously been identified but ethnicity is a new correlate which warrants further exploration. It is possible that Welsh ethnic identification also reflects class status since incomers are less likely to be blue collar working class (Table 7).

Looking more closely at Table 7 , which identifies the variable values associated with isolation and loneliness, some of the overlaps and discontinuities can be explored further. The table distinguishes between objective and subjective variables. Some variables are more difficult than others to categorise because self-assessments can be affected by the emotional state of the respondent. Self-assessed health is clearly one of these. However, we have also classified the length of time respondents had known their confidant as subjective since the perception of having a confidant is likely to be subjective.

The outcome suggests that while the distinction between social isolation as an objective state and loneliness as a subjective state generally holds, the refined model indicates that it may not be so clearcut. As we might have previously suggested (Wenger I983) selfassessed loneliness results from more subjective factors than loneliness based on the aggregate measure. Whilst it is not possible to prove the 
direction of causality, particular objective aspects of social isolation appear to predispose older people to loneliness: widowhood, living alone and support network type. Also, some of the subjective variable correlates of loneliness may exacerbate social isolation: self-assessed poor health (leading to restricted mobility) and low morale.

Finally, it is emphasised that some potentially significant correlates were not available in the North Wales data set. These may be characterised as possible outcome variables resulting from isolation and/or loneliness. Mortality and admission to residential care have been found to be correlated with both isolation and loneliness. Isolation has further been linked with poor rehabilitation and mental illness; and loneliness with depression. Both are associated with low morale. The importance of network type for both isolation and loneliness suggests that interventions at the network level which increase contact and interaction are likely to have preventative outcomes in terms of loss of independence and health maintenance as well as improving quality of life. Further work using longitudinal data and looking prospectively at change and the correlates of changes will make it possible to explore further the inter-relationships between isolation, loneliness and other variables.

\section{References}

Abrams, Mark. 1974. Attitudes of the Retired Elderly, Age Concern Manifesto, 32. Age Concern England, London.

Abrams, Mark 1983. People in their Late Sixties: a longitudinal survey of ageing, Part I, survivors and non survivors. Age Concern Unit, London.

Andersson, Lars 1990. Narcissism and loneliness. International Journal of Aging and Human Development, 30 (2), $8 \mathrm{I}-94$.

Arling, Greg 1980. The elderly widow and her family, neighbours and friends. In Fuller, M. M. and Martin, C. A. (eds.) The Older Woman. Charles C. Thomas, Springfield, Ill., 1 70-189.

Asiel, M. 1987 . Does loneliness have any impact on health and health care? Paper presented at International Association of Gerontology Conference, Brighton, England.

Bengtson, V. and Kuypers, J. 1985. The family support cycle. In Munnichs, J., Mussen, P., Olbrich, E. and Coleman, P. (eds.) Lifespan and Change in a Gerontological Perspective, Academic Press, Orlando, Florida, 257-274.

Bennett, Ruth i 980 . The concept and measurement of social isolation. In Bennet, R. (ed.) Aging, Isolation and Resocialization. Van Nostrand Reinhold Co., New York, $9^{-26}$.

Berardo, F. 1967. Social Adaptation to Widowhood Among a Rural-urban Aged Population. Tech Bul. No. 689, Pullman, Washington: Washington Agricultural Experiment Station, College of Agriculture, Washington State Univ.

Berg, S., Melestrom, D., Persson, G. and Svanberg, A. 1981. Loneliness in the Swedish aged. Joumal of Gerontology, 36, 342-349. 
Berkman, L. J. and Syme, S. L. 1979. Social Networks, lost resistance and mortality: a nine-year follow-study of Alameda County residents. American Journal of Epidemiology, 109, 257-273.

Blum, Alan 1964. Social structure, social class and participation in primary relationships. In Shostak, A. and Gomberg, W. (eds.) Blue Collar World. Prentice Hall, Tanglewood Cliffs, N.J., I 45-207.

Brocklehurst, J. 1978. Ageing and health. In Hobman, D. (ed.) The Social Challenge of Ageing. London, Croom Helm, I 49-1 7 I.

Brown, G. W. and Harris, T. 1978. Social Origins of Depression: A Study of Psychiatric Disorder in Women. Tavistock Publications, London.

Bury, M. and Holme, A. 1990. Quality of life and social support in the very old. Journal of Aging Studies, 4, 4, 345-357.

Carey, R. G. 1977. The widowed: a year later. Journal of Counselling Psychology, 24, I 25-131.

Challis, D. J. 1982. The measurement of outcome in social care of the elderly. Fournal of Social Policy, ro, 1 79-208.

Chappell, Neena L. and Badger, Mark 1989. Social isolation and well-being. The Journal of Gerontology, 44 (5), $169-176$.

Christ, L. M. and Muller, M. T. I991. Social desirability in surveys of the elderly: a secondary analysis of loneliness measures in Dutch research projects. Paper presented at II European Congress of Gerontology, Madrid $11-14$ September.

Dean, A. and Lin, N. I 977 . The stress-buffering role of social support. The Journal of Nervous and Mental Disease, 165, 6, 403-417.

Department of Health (DoH) 1989. Caring for People: Community Care in the Next Decade and Beyond. Government White Paper HMSO, London.

Department of Health (DoH) I 990 a. Community Care in the Next Decade and Beyond: Policy Guidance. HMSO, London.

Department of Health (DoH) 1990b. Caring for People: Policy Guidelines. HMSO, London.

Dibner, A. S. $198 \mathrm{I}$. Is there a psychology of the rural aged? In Childs, A. and Melton, G. (eds.) Rural Psychology. Plennar Press, Boston.

Elias, Norbert 1986 . The Loneliness of the Dying. Blackwell, Oxford.

Francis, B., Green, M. and Payne, C. 1993. Glim 4 Manual. Clarendon Press, Oxford.

Fitzgerald, Frances 1986. Sun City. In Cities on a Hill: a journey through contemporary American cultures. Simon and Schuster, Inc., New York (reprinted Picador Books, 1987), 203-245.

Freeman, Hugh 1988. Psychosocial effects of social isolation in the elderly. Danish Medical Bulletin: Journal of the Health Sciences, Gerontology: Special Supplement Services, 6, $13^{-23}$.

Golberg, E. M. 1979. Helping the Aged. Allen and Unwin, London.

Gottlieb, B. H. and Schroter, Candice 1978. Collaboration and resources exchanged between professional and natural support systems. Professional Psychologist, 9, 4, $614-622$.

Grant, G. I98I. Monitoring Social Services Delivery in Rural Areas: Intake Cases in Two Contrasting Teams. Working Paper No. 14, Centre for Social Policy Research and Development, University of Wales, Bangor, Gwynedd.

Grant, V.J. 1988. Return to the Community: A Way Back for Isolated and Depressed Elderly People. Paper presented to International Congress of Anthropological and Ethnological Sciences, Zagreb.

Griffiths, Sir Roy 1 988. Community Care: Agenda for Action. A report to the Secretary of State for Social Services. HMSO, London.

Hadley, Roger and Webb, Adrian 1974. Loneliness, Social Isolation and Old People: Some Implications for Social Policy. Age Concern, London. 
Hadley, Roger, Webb, Adrian and Farrell, Christine 1975. Across the Generations. George Allen \& Unwin, London.

Halmos, Paul 1952. Solitude and Privacy: A Study of Social Isolation, Its Causes and Therapy. London.

Harris, L. and Associates 1974. The Myth and Reality of Aging in America. National Council of Aging, Washington D.C.

Harris, L. and Associates 1981. Aging in the Eighties: America in Transition. National Council on Aging, Washington D.C.

Havinghurst, Robert 1978. Ageing in western society. In Hobman, David (ed.) The Social Challenge of Ageing. Croom Helm, London.

Hazan, Haim 1980. The Limbo People: A Study of the Constitution of the Time Universe among the Aged. Routledge and Kegan Paul, London.

Hovaguimian, T., Grab, B. and Stuckelberger, A. 1988. Psychosocial problems and the health of the elderly with special reference to social isolation. Danish Medical Bulletin: Journal of the Health Sciences Gerontology: special supplement series, 6, 2-7.

Hunt, Audrey 1978. The Elderly at Home: A Study of People Aged Sixty-five and Over Living in the Community in England in 1976. Social Survey Division, OPCS. HMSO, London.

Hyman, M. D. 1972. Social isolation and performance in rehabilitation. Journal of Chronic Disease, 25, 85-97.

Jerrome, Dorothy i 982 . Encounters with Death. Paper presented at the Annual Conference, British Society of Gerontology, Brighton.

Jerrome, Dorothy 1991. Loneliness: possibilities for intervention. Journal of Aging Studies, 5 (2), 195-208.

Jerrome, Dorothy 1992. Good Company: An Anthropological Study of Old People in Groups. Edinburgh University Press, Edinburgh.

Jones, D. A., Victor, C. R. and Vetter, N. J. I $^{8} 5$. The problem of loneliness in the elderly in the community: characteristics of those who are lonely and the factors related to loneliness. Journal of the Royal College of General Practitioners, 35, I 36-1 39.

Kivett, Vira R. 1979. Discriminators of loneliness among the rural elderly: implications for intervention. The Gerontologist, 19 ( 1 ), , $108-1$ I 5 .

Knipscheer, Kees, C. P. M. Ig88. Social support and isolation as health related variables. Danish Medical Bulletin: Journal of the Health Sciences Gerontology: Special Supplement Series 6, 23-26.

Koedoot, N. and Hommel, A. 1993. Case management and incentives for the elderly: findings from the Rotterdam experiment. In Coolen, J. A. I. (ed.) Changing Care for the Elderly in the Netherlands: Experience and Research Findings from Policy Experiments. Van Gorcum, Assen/Maastricht, 71-89.

Larsen, R., Zuzanek, J. and Mannell, R. 1985. Being alone versus being with people: disengagement in the daily experience of older adults. Journal of Gerontology, 40, 375-38 I.

Lowenthal, M. F. 1964. Social isolation and mental illness in old age. American Sociological Review, 29, 54-70.

Lowenthal, M. and Robinsøn, B. I976. Social networks and isolation. In Binstock, R. and Shanas, E. (eds.). Handbook of Ageing and the Social Sciences. Van Nostrand Rheinhold, N.Y.

Lynch, J. J. 1977. The Broken Heart: The Medical Consequences of Loneliness in America. Basic Books, New York.

Mulligan, M. A. and Bennet, R. 1977/8. Assessment of mental health and social problems during multiple friendly visits: the development and evaluation of a friendly visiting programme for the isolated elderly. International Journal of Aging and Human Development, 8 ( 1 ), $43 \mathrm{ff}$. 
Mullins, L. C., Johnston, D. P. and Anderson, L. 1988. Social and emotional isolation among the elderly: a conceptual view of loneliness. Danish Medical Bulletin: Journal of the Health Sciences, Gerontology: Special Supplement Series, 6, 26-29.

Mullins, L. G. and Mushel, M. 1992. The existence and emotional closeness of relationships with children, friends and spouses: the effect on loneliness among older persons. Research on Aging, 14 (4), 448-470.

Murphy, E. 1982. Social Origins of depression in old age, British Journal of Psychiatry, 141, 135-I42.

Murphy, E. 1983. The prognosis of depression in old age. British Joumal of Psychiatry, 142, II I-I I 9 .

Murphy, E. 1987. Excess Mortality in Late-life Depression. Paper presented International Association of Gerontology Conference, Brighton, England.

Palmore, E. 1976. Total chance of institutionalization among the aged, Gerontologist, I6c, 504-507.

Peters, G. R. and Kaiser, M. A. 1985 . The role of friends and neighbours in providing social support. In Sauer, William J. and Coward, Raymond T. (eds.) Social Support Networks and the Care of the Elderly. Springer, New York.

Power, Brian ig8o. Old and Alone in Ireland. St. Vincent de Paul, Dublin.

Qureshi, H. and Walker, A. 1989. The Caring Relationship, Elderly People and their Families. Macmillan, Basingstoke.

Rodstein, M., Savitsky, E. and Starkman, R. I976. Initial adjustment to a long term care institution: behavioural aspects. Foumal American Geriatric Society, XXIV (2), $65^{-7}$ I.

Ross, H. E. and Kedward, H. B. 1976. Demographic and social correlates of psychogeriatric hospitalization. Social Psychiatry, I1 (3), 1 2 1-1 26.

Salloway, M. 1983 . Social Networks in Diseases of Aging. Paper delivered to International Congress of Anthropological and Ethnological Sciences, Quebec.

Seabrook, Jeremy, 1973. Loneliness. Maurice Temple Smith Ltd., London.

Shanas, Ethel et al. I 968 . Loneliness, isolation and desolation in old age. In Shanas, E., Townsend, P. and Wedderburn, D. (eds.) Old People in Three Industrial Societies. Routledge and Kegan Paul, London, $271-276$.

Sheldon, J. H. 1948. The Social Medicine of Old Age: Report of an Inquiry in Wolverhampton. Oxford University Press, London.

Sinclair, I., Parker, R., Leat, D. and Williams, J. I9go. The Kaleidoscope of Care: $A$ Review of Research on Welfare Provision for Elderly People, HMSO, London.

Stevenage Development Corporation, Social Relations Department 1973. Sheltered Housing in Stevenage.

Thompson, M. K. I973. Adaptations of loneliness in old age. Proceedings of the Royal Society of Medicine, 66, 887 .

Tornstam, Lars I98I. Daily Problems in Various Ages. Paper presented to XII International Congress of Gerontology, Hamburg, I I-I 7 July.

Tornstam, L. 1989 . Faces of Loneliness. Paper presented to XIV International Congress of Gerontology, Acapulco, Mexico, 18-23 July.

Townsend, Peter 1965 . The effects of family structure on the likelihood of admission to an institution in old age: the application of a general theory. In Shanas, E. and Streib, G. (eds.) Social Structure and the Family: Generational Relations. Prentice Hall, Englewood Cliffs, N.J.

Townsend, Peter i 968 . Isolation, desolation and loneliness. In Shanas, E., Townsend, P. and Wedderburn, D. (eds.) Old People in Three Industrial Societies. Routledge, London, 258-287.

Townsend, Peter and Tunstall, S. 1973. Sociological explanations of the lonely. In Townsend, P. The Social Minority. London, 257-263. 
Weeks, J. and Cuellar, J. 1981 . The role of family members in the helping networks of older people. The Gerontologist, 21, 388-394.

Wenger, G. Clare 1983 . Loneliness: a problem of measurement. In Jerrome, Dorothy (ed.) Ageing in Modern Society. Croom-Helm, London, 145-167.

Wenger, G. Clare 1984a. Surviving in the Community: Some Demographic and Social Factors. Working Paper No. 33, Care Networks Project. Department of Social Theory, University College of North Wales, Bangor, $22 \mathrm{pp}$.

Wenger, G. Clare $1984 b$. The Supportive Network: Coping with Old Age. George Allen and Unwin, London.

Wenger, G. Clare 1989 . Support networks in old age: constructing a typology. In Jefferys, M. (ed.) Growing Old in the 2oth Century. Routledge, London, I66-185.

Wenger, G. Clare $1992 a$. Help in Old Age: Adaptation to Change. Institute of Human Ageing, Liverpool University Press, Liverpool.

Wenger, G. Clare $1992 b$. Morale in old age: a review of the literature International Journal of Geriatric Psychiatry, 7, 699-708.

Wenger, G. Clare and Scott, Anne 1994. Change and Stability in Support Network Type: findings from the Bangor Longitudinal study. Paper presented at the International Sociology congress, Bielefeld, Germany, July.

Whittington, H. J. 1977. Widowhood in a Seaside Resort: A Study of the Situation of Some Elderly Widows and Their Response to Bereavement. M. Litt. thesis, Department of Social Administration, University of Lancaster.

Wilkes, Ruth 1978. General philosophy and attitudes to ageing. Social Work Today, 9, $45,14-16$.

Wilkin, D., Hughes, B. and Jolly, D. J. 1985. Quality of care in institutions. In Arie, T. (ed.) Recent Advances in Psychogeriatrics. Churchill Livingstone, London.

\section{Appendix A - Support network typology}

The support network typology referred to in this paper is based on earlier work from the longitudinal research on ageing on which this paper is based (Wenger 1989). Five support network types were identified on the basis of the following factors:

(i) the availability of local close kin

(2) the level of involvement of family, friends and neighbours and

(3) the level of interaction with the community and voluntary groups.

The networks are named on the basis of the nature of the old person's relationship to the support network. The first three types are based on the presence of local kin, the other two types reflect the absence of local kin:

(1) Local family dependent

(2) Locally integrated

(3) Local self-contained

(4) Wider community focused

(5) Private restricted. 
The five networks identified can be summarised as follows:

(I) The local family dependent support network has primary focus on close local family ties with few peripheral friends and neighbours. It is often based on a shared household with, or near to, an adult child, usually a daughter. Community involvement is generally low. All support needs are met by relatives. These networks tend to be small and the elderly people are more likely to be widowed, older and in less good health than those with other types of networks.

(2) The locally integrated support network includes close relationships with local family, friends and neighbours. Many neighbours are also friends. Usually based on long-term residence and active community involvement in church and voluntary organisations in the present or recent past. These networks tend to be larger on average than others.

(3) The local self-contained support network typically has arms-length relationships or infrequent contact with at least one relative living in the same or adjacent community or neighbourhood, often a sibling, niece or nephew. Childlessness is common. Reliance is focused on neighbours but elderly people with this type of network tend to adopt a household-focused life-style and community involvement, if any, tends to be low key. Networks tend to be smaller than average.

(4) The wider community focused support network is associated with active relationships with distant relatives, usually children and high salience of friends and neighbours. Absence of local kin is typical. The distinction between friends and neighbours is maintained. The old people are generally involved in community and/or voluntary organisations. This type of network is frequently associated with retirement migration and is commonly middle class or skilled working class adaptation. Networks are larger than average.

(5) The private restricted support network is typically associated with absence of local kin, other than in some cases a spouse, although a high proportion are married. Contact with neighbours is minimal. These old people have few nearby friends and a low level of community contacts or involvements. The network type subsumes two sub-types: independent married couples and dependent elderly persons who have withdrawn or become isolated from local 
involvement. In many cases a low level of social contact represents a lifelong adaptation. Networks are smaller than average.

\section{Appendix B - Statistical details of model building}

Cross-sectional analysis of isolation measure, $(\mathrm{N}=498)$ - cell values are $p$-values based on F-ratio test, 'IN' indicates a selected variable which remains in the model

\begin{tabular}{|c|c|c|c|c|c|c|c|c|}
\hline \multirow{2}{*}{$\begin{array}{l}\text { Explanatory variables } \\
\text { Age } \\
\text { Sex }\end{array}$} & \multicolumn{5}{|c|}{ Stage $I$} & \multicolumn{3}{|c|}{ Stage 2} \\
\hline & $*$ & 0.11 & & & & & & \\
\hline Marital status & * & IN & IN & IN & IN & FIXED & FIXED & FIXED \\
\hline Social class & 0.01 & 0.001 & * & IN & IN & FIXED & FIXED & FIXED \\
\hline Ethnicity & 0.68 & & & & & & & \\
\hline Arrival age & 0.17 & & & & & & & \\
\hline Years widowed & $*^{*}$ & $*$ & IN & IN & IN & FIXED & FIXED & FIXED \\
\hline Income & * & 0.09 & & & & & & \\
\hline Network type & * & * & * & 0.002 & IN & FIXED & FIXED & FIXED \\
\hline Subjective variables & & & & & & & & \\
\hline Health & 0.97 & & & & & & & \\
\hline Health limited activities & $0.7 \mathrm{I}$ & & & & & & & \\
\hline Morale & $*$ & & & & & * & 0.01 & IN \\
\hline Presence of friends & 0.03 & & & & & 0.03 & 0.10 & \\
\hline Wish for more & 0.02 & & & & & 0.03 & 0.13 & \\
\hline Confidant & * & & & & & $0.00 \mathrm{I}$ & 0.17 & \\
\hline Years known confidant & * & & & & & * & IN & IN \\
\hline $\mathrm{R}^{2}$ & & & & & 0.32 & & & 0.39 \\
\hline
\end{tabular}

${ }^{*} p<0.0001$.

Cross-sectional analysis of self-assessed loneliness $\left(\mathrm{N}=49^{8}\right)$ cell values are $p$-values based on likelihood ratio test $\chi^{2}$, 'IN' indicates a selected variable which remains in the model.

\begin{tabular}{lcccccccc}
\hline Explanatory variables & \multicolumn{4}{c}{ Stage I } & \multicolumn{5}{c}{ Stage 2 } \\
\hline Constant & IN & IN & IN & IN & IN & IN & IN & IN \\
Objective Measures & & & & & & & & \\
Sex & $*$ & 0.14 & - & - & - & - & - & - \\
Age & 0.07 & - & - & - & - & - & - & - \\
Marital status & $*$ & IN & IN & IN & IN & IN & IN & IN \\
Number of years widow & 0.02 & 0.17 & - & - & - & - & - & - \\
Household composition & $*$ & $*$ & $*$ & IN & IN & IN & IN & IN \\
Network type & $*$ & $*$ & IN & IN & IN & IN & IN & IN \\
Income & $*$ & 0.29 & - & - & - & - & - & -
\end{tabular}


Cross-sectional analysis of self-assessed loneliness (cont.)

\begin{tabular}{lclllllll}
\hline Explanatory variables & \multicolumn{3}{c}{ Stage I } & \multicolumn{5}{c}{ Stage 2 } \\
\hline Social class & 0.18 & - & - & - & - & - & - & - \\
Ethnicity & 0.22 & - & - & - & - & - & - & - \\
Parenthood & 0.31 & - & - & - & - & - & - & - \\
Arrival age in community & 0.07 & - & - & - & - & - & - & - \\
Subjective Measures & & & & & & & & \\
Presence of friends & 0.01 & & & & 0.25 & - & - & - \\
Self-assessed health & $*$ & & & & $*$ & $*$ & IN & IN \\
Health limited activities & $*$ & & & & $*$ & $*$ & 0.09 & - \\
Confidant & $*$ & & & & 0.04 & 0.05 & 0.08 & - \\
Length known confidant & $*$ & & & & 0.005 & 0.0 I & 0.04 & IN \\
Wish for more friends & $*$ & & & & $*$ & IN & IN & IN \\
& & & & & & & & \\
\hline
\end{tabular}

$* p<0.0001$.

Cross-sectional analysis of loneliness measure $(\mathrm{N}=498)$ - cell values are $p$-values based on likelihood ratio test $\chi^{2}$, 'IN' indicates a selected variable which remains in the model

\begin{tabular}{|c|c|c|c|c|c|c|}
\hline \multirow{2}{*}{$\begin{array}{l}\text { Objectives } \\
\text { Age }\end{array}$} & \multicolumn{4}{|c|}{ Stage I } & \multicolumn{2}{|c|}{ Stage 2} \\
\hline & 0.03 & 0.33 & & & & \\
\hline Sex & 0.24 & & & & & \\
\hline Marital status & $0.1 \mathrm{I}$ & & & & & \\
\hline Household composition & 0.02 & 0.003 & IN & IN & IN & IN \\
\hline Social class & 0.16 & & & & & \\
\hline Ethnicity & * & 0.007 & 0.003 & IN & IN & IN \\
\hline Parenthood & O.I I & & & & & \\
\hline Arrival age & 0.12 & & & & & \\
\hline Years widowed & 0.04 & 0.10 & & & & \\
\hline Income & 0.23 & & & & & \\
\hline Network type & $*$ & IN & IN & IN & & \\
\hline Subjective Variables & & & & & & \\
\hline State of health & $*$ & & & & 0.02 & IN \\
\hline Health limited activities & $*$ & & & & 0.06 & \\
\hline
\end{tabular}

$* p<0.0001$. 